Bond University

Research Repository

\title{
Managing dynamic work teams for innovation: integrating knowledge management and organisation behaviour using the DFO model
}

Mir, Farhan; Siddiquei, Ahmad; Hayyat, Muhammad; Razzaq, Muhammad

Published in:

International Journal of Knowledge and Learning

DOI:

10.1504/IJKL.2020.111140

Licence:

Other

Link to output in Bond University research repository.

Recommended citation(APA):

Mir, F., Siddiquei, A., Hayyat, M., \& Razzaq, M. (2020). Managing dynamic work teams for innovation:

integrating knowledge management and organisation behaviour using the DFO model. International Journal of Knowledge and Learning, 13(4), 313-338. https://doi.org/10.1504/IJKL.2020.111140

\section{General rights}

Copyright and moral rights for the publications made accessible in the public portal are retained by the authors and/or other copyright owners and it is a condition of accessing publications that users recognise and abide by the legal requirements associated with these rights.

For more information, or if you believe that this document breaches copyright, please contact the Bond University research repository coordinator. 


\title{
Managing Dynamic Work Teams for Innovation: Integrating Knowledge Management and Organization Behavior using the Dynamic Fractal Organization (DFO) Model
}

\author{
Author \# 1: Farhan Mir \\ Affiliation: Bahauddin Zakariya University, Pakistan \\ Email: farhanmir@bzu.edu.pk \\ Address: Bosan Road, Multan, Pakistan \\ Biography: Farhan Mir is currently serving as an Assistant Professor in the Institute of Management Sciences, \\ Bahauddin Zakariya University, Pakistan. Farhan has been serving in the academic industry for almost 15 years \\ with a successful demonstration of professional ability as an academic and as an administrator. He has expanded \\ his portfolio as a lead consultant trainer at the Management Institute for Research and Skill Development (MIRS), \\ intending to work for the development of the deprived ones. Farhan's research interests include knowledge and \\ technology management, leadership, and teams.
}

\section{Author \# 2/Corresponding Author: Ahmad Nabeel Siddiquei, Ph.D.}

Affiliation: Bond University, Australia

Email: asiddiqu@bond.edu.au

Address: 14 University Drive, Robina, Gold Coast, Australia

Biography: Ahmad Siddiquei is currently serving as a Teaching Fellow (Adjunct) at Bond University, Australia. Ahmad has recently completed his Ph.D. in Management, specializing in leadership and project teams. Ahmad's research work has appeared in highly recognized journals. His research interest includes leadership in teams, projects, and the environment.

Author \# 3: Muhammad Faisal Hayyat

Affiliation: GeniTeam, Pakistan

Email: faisalhayat30@gmail.com

Address: Ferozpur Road, Lahore, Pakistan

Biography: Faisal Hayyat has been serving as a Human Resource Manager in GeniTeam (software development company). He has held several managerial positions in the Information Technology sector of Pakistan. He has undergraduate and postgraduate degrees are in Business Management, specializing in Human Resource Management and Information Technology.

\section{Author \# 4: Muhammad Ali Razzaq}

Affiliation: Griffith University

Email: ali.razzaq@griffithuni.edu.au

Address: 58 Parklands Drive, Southport, Gold Coast, Australia

Biography: Muhammad Razzaq is a Ph.D. student at Griffith University, Australia. He has recently completed his MBA from Air University, Pakistan. Muhammad is a young researcher with research interests related to sustainability, social marketing, and human resource management 


\begin{abstract}
In contemporary knowledge-creating companies, teams must develop a systematic approach to integrate and create knowledge throughout the organization in order to adapt to the profoundly changing environment. We employed the Dynamic Fractal Organization (DFO) model presented by Ikujiro Nonaka, Kodama, Hirose, and Kohlbacher (2014) as a knowledge lens and as an appropriate management model to propose the existence and development of dynamic teams aiming to enhance their knowledge-creating ability at a rapid pace for sustainable innovation. The proposed framework highlights the significance of knowledge culture in promoting knowledge vision, trust between members, commitment and willingness for knowledge creation, teamwork orientation, and an ongoing contribution of distributed phronesis based leadership that facilitates dynamic knowledge creation. A qualitative case study approach was employed based on empirical data from 24 in-depth interviews, which were triangulated with evidence from a detailed document analysis. Empirical insights gathered from an app development company GenITeams were evaluated to have a holistic overview of the underlying phenomenon. Case study findings confirmed the existence of the dynamic knowledge-creating mechanism adopted by GenITeams that encourages team members to interact in a multi-layered networked setting. Results also revealed that GenITeams could develop a management model that fosters innovation through continuous upward knowledge creation spiral. Finally, we discuss the significant outcomes and implications of the integration of knowledge management and organizational behavior models.
\end{abstract}

Keywords: Sustained Innovation; Dynamic Fractal Model; Knowledge Creation within dynamic Teams; App Development Company 


\section{Introduction}

The future success of business firms is dependent on innovation. Successful firms rely on teams to innovate and stay relevant in the marketplace. As proposed in the knowledge creation theory by Nonaka (1994), the interaction between individuals helps to harness knowledge sharing among teams. Successful teams engage themselves in various knowledge exchanges to engender opportunities for sustainable innovation in an upward spiraling process (Tan \& Tan, 2020b). However, teams need shared space within the organization for effective interaction and functioning to sustain knowledge creation, a notion termed as "Ba" (Nonaka, 1994; Nonaka, Toyama, \& Byosiere, 2003). Traditional knowledge-creating models are not in a position to provide sustainable ways to innovate (Ikujiro Nonaka, Hirose, \& Takeda, 2016; Tan \& Tan, 2020b). Scholars have noted that there is a need to propose more robust models that could provide clues on how to integrate innovative knowledge-creating competencies throughout the organization (Argote, 2012; Nonaka, Nishihara, \& Kawada, 2018).

In this study, the dynamic fractal model presented by Nonaka et al. (2014) on dynamic knowledge creation is proposed as a management model i.e. by using the metaphor of fractals, i.e., the "invisible sphere of the knowledge triad" firms could manage the highly complex routines of dynamic knowledge creation. Dynamic fractal organizations are defined as organizations that "realize requisite variety through multi-layered networks of_ba_to achieve knowledge triad relationships and make use of knowledge creation and exploitation dynamically." (Nonaka et al., 2014, p. 140). Application of this new form of the organizational model is already yielding competitive advantage for knowledge-creating companies in industries like automobiles, electronics, smart mobiles, computing, and many more (Nonaka et al., 2014). We propose two major influencing factors in our framework - cultural values and leadership that 
improves the dynamic team's ability and motivation for knowledge creation within the dynamic fractal organization model. Also, we take a stance similar to that of Nonaka et al. (2014) on knowledge exploration and exploitation processes. In this paper, these are not two distinct processes rather could co-exit and complement each other throughout the knowledge creation process. We believe that the dynamic fractal organizational model, when conceived as a management tool, could provide a novel and practical approach for modern firms in multiple ways. It promises to not only be the right organizational model for dynamic knowledge creation based on knowledge sharing within a shared context but also propose a revitalized leadership style for fostering practical wisdom across multiple levels of the organization.

Next, we present the essence of the dynamic fractal organizations presented by Nonaka et al. (2014), followed by a discussion on our proposed conceptual framework by linking critical concepts of the model with relevant research propositions. Case study findings from an app development company GenITeams will provide empirical evidences on the model thereafter. Lastly, the discussion and conclusion section will provide critical conclusions and future research directions for both academics and practitioners.

\section{Dynamic Fractal Organizations}

Dynamic fractal organizations are defined as organizations that "realize_requisite variety through multi-layered networks of _ba_achieve knowledge triad relationships and make use of knowledge creation and exploitation dynamically." (Nonaka et al., 2014, p. 140). Application of this new form of the organizational model is already yielding competitive advantage for knowledge-creating companies in industries like automobiles, electronics, mobile and computing (Nonaka et al., 2014). We begin with re-conceptualizing knowledge-creating theory by highlighting the importance of the multi-layered ' $\mathrm{Ba}$ ' and the emergence of the third type of 
knowledge, i.e., phronesis. This theoretical buildup will enable us to explain the fundamental and essential components of the dynamic fractal organization in detail.

Knowledge creation and its impact on the organization's performance have been studied throughout the last three decades, and the relationship has emerged as an essential research stream in the field of knowledge management (Nonaka, 1994; Nonaka et al., 2003). The initial work on knowledge management focused on information processing in the domain of information systems, which gradually shifted to examine knowledge creation and management as a process. Extant literature suggests a paradigm shift and emphasizes the significance of finding theoretical developments in the domain of knowledge creation and further its impact on organizational performance (Nonaka et al., 2003). Nonaka has a tremendous contribution to the development of knowledge creation theory as he proposed the essence of the knowledge-creating company (Ikujiro Nonaka, 1994) and the knowledge creation processes with the help of the Japanese term "Ba" (Ikujiro Nonaka, 1994). He also discussed the various internal and external factors that supported his knowledge creation process, as presented in Figure 1.

***Insert Figure 1 about here***

Nonaka’s work (1994) emphasized the role of leadership, new organizational structure, and development of new learning practices. His theory highlights the importance of social context in which the knowledge is created and classifies knowledge as contextual and related to a specific circumstance (Jakubik, 2008). Importantly it shifts the focus from individual-level conceptualization of knowledge towards the group and organizational setting by pinpointing the need for requisite verity as an essential element. Similarly, Ikujiro Nonaka and Toyama (2007) proposed a model that frames the knowledge creation process (SECI) with the help of ' $\mathrm{Ba}$ ' in continuous interaction with the environment creating new knowledge stock. The process, 
however, needs a clear knowledge vision from a management perspective. The main elements of the model i.e. SECI, Ba and resulting knowledge revolves around knowledge conversion process from individual to teams to organization and eventually to the operational environment referred as the knowledge "ecosystem".

Multi-layered networked Ba. Nonaka (1994) classified the whole knowledge-creating company as a flexible and adaptive configuration of multi-layered Ba. According to him, the configuration of formal structure based on hierarchies alongside the simultaneous existence of informal social interaction in the shared space of Ba presents the co-existence of both systems in a balance. It is classified as the source of the knowledge creation mechanism. Hence, as a manager (team leader) in a knowledge-creating company, we need to acknowledge the importance of formal organizational settings as well as its relationship with the network of $\mathrm{Ba}$ in order to create a shared sense of meaning at the workplace. The concept of $\mathrm{Ba}$ is now admired as one of the widely acknowledged facets of knowledge creation systems derived from the Japanese notion of "space for interaction" (Nonaka et al., 2000).

***Insert Figure 2 about here***

Figure 2. represents the conceptualization of $\mathrm{Ba}$, where team members mostly have physical interaction but could also use different types of Ba that could facilitate individuals and teams using social interaction and technology. By closely monitoring various types of Ba (Nonaka et al., 2000), we could see categorization based on how the members interact through various mechanisms. For instance, physical Ba (for face-to-face interaction), virtual Ba (utilizing Internet and technological options), and mental $\mathrm{Ba}$ (using values and beliefs shared by the organizational members). Moreover, we can also envision further classifications of $\mathrm{Ba}$, based on the way they become active in the knowledge creation processes. For example, they are 
originating $\mathrm{Ba}$, dialoguing $\mathrm{Ba}$, systemizing $\mathrm{Ba}$, and exercising $\mathrm{Ba}$ corresponding to the four phases of SECI.

\section{Dynamic Fractal Organization Model}

Progressing his knowledge creation model in a series of writings, Nonaka presented a new organizational theory based on a dynamic fractal framework (Nonaka et al., 2014). This theory posits that the invisible spheres of knowledge triads networked through multi-layered $\mathrm{Ba}$ in the organization result in practical wisdom (phronesis - a new type of knowledge). The purpose of this model is to answer, 'which form should an organization take for dynamic synthesis of exploration and exploitation?' Responding to this call, the resent study presents a novel model that revolves around an organizational setting based on fractals, where each fractal dynamically builds around the conversion of tacit-explicit-phronesis and the simultaneous conversion of exploration and exploitation.

Nonaka, in his knowledge creation theory, elaborated the simultaneous and continuous conversion between the tacit and explicit knowledge as the source of new knowledge. The bodily experiences translated into organizational memory and documents, and the upward spiral could take this knowledge creation to a new higher level (Nonaka \& Von Krogh, 2009). However, in this new model based on knowledge triads (Figure 3. knowledge triad), Nonaka et al. (2014) supplemented the third type of knowledge ( i.e., phronesis, inspired from the writings of Aristotle) which emerges from the synthesis of the explicit and tacit knowledge during the upward spiraling process.

***Insert Figure 3 about here***

According to this model, phronesis is an essential component of knowledge creation for sustainable innovation - a sense of contextual value judgment while keeping the focus on the 
common goals and objectives. It is also classified as the judgment about the goodness of things as the common good, which is associated with knowledge workers while they are practically engaged in projects and knowledge-creating processes. Nonaka et al. (2014) recommended the necessity for distributed phronesis, i.e., leaders should be able to foster this greater sense and ability in their counterparts and team members through guidance and sharing.

Nonaka et al. (2014) defined fractal organization as "Organizations that comprehend requisite variety through multi-layered networks of Ba to achieve knowledge triad relationships and use knowledge creation and exploitation dynamically—resulting in sphere-like invisible organizations. Nonaka and the co-authors have introduced their knowledge creation model as an organizational theory level framework by presenting the organizations as not only an active participant in its environment but also an actor that continuously creates and utilizes knowledge through a synthesizing process based on a knowledge triad (Tacit, Explicit and Phronesis). This fractal organization according could be one of the best knowledge related framework applicable in both structured and dynamic circumstances alike, as it generates sustainable knowledge transfers within and across the organizational boundaries using multiple dynamic Ba. The focus is placed on the leadership to drive this fractal organization through enhancing contextual judgment and the upward spiral convergence of various types of knowledge. Leaders, through their vision, could assess the level of connection between various fractals horizontally and vertically, thus infusing the practical wisdom at all levels of the organization.

***Insert Figure 4 about here***

\section{Organizational Culture for Dynamic Fractal Model}

After concentrating on the dynamics of the fractal model as a sustainable knowledgecreating mechanism, we can now focus on internal environmental configurations for the 
development and stimulation of dynamic fractal organization. A thorough review of the literature indicates a profound stream of conceptual and empirical findings that investigated the link between various aspects of knowledge management and organizational culture (Davenport \& Prusak, 1998; Jeng \& Dunk, 2013). It will be very time consuming to explore cultural influences in the context of knowledge creation through the dynamic fractal model. Nonaka has specified about the importance of knowledge vision, teamwork and sense of shared practices among team members on knowledge creation theory in his empirical findings (Nonaka et al., 2014; Nonaka \& Peltokorpi, 2006; Nonaka \& Toyama, 2007; Nonaka et al., 2003; Nonaka et al., 2000; Nonaka \& Von Krogh, 2009).

Drawing theoretical support from Social Exchange Theory (Marlien, Maskur, \& Setiawan) and Social Capital Theory (SCT), we investigate the impact of cultural influences on organizational member's attitudes and behaviors concerning other co-members, especially, in their collective efforts as teams. The theoretical underpinning of Social Exchange Theory and Social Capital Theory is in accord with the work of Xue, Bradley, \& Liang (2011), who associates the impact of cultural influences on organizational member's attitudes and behaviors about other co-members, mainly, in their collective efforts as teams. Culture can be defined in so many ways; it is regarded as a value system that defines truth and goodness for an organization (Nonaka \& Toyama, 2007), while others have examined it in terms of how a person identifies himself within an organizational setting and relates his values and beliefs with respect to that organization (Song, 2008; Song \& Chermack, 2008). This study differs from previous studies done in the past from the viewpoint that it would be primarily looking at culture as a value system in terms of knowledge management, Nonaka and Takeuchi (1995) associated knowledge, 
and culture as an essential part of the grand system, whereas Hong, Kim, Kim, and Leem (2008) have classified tacit knowledge as majorly constituted of cultural elements.

The debate on the role of culture in knowledge management is not nascent, and the literature suggests that there has been a constant debate in academic circles on finding linkages between knowledge management supported through cultural values. Erstwhile literature recommends the use of terms like "knowledge friendly culture" (Davenport \& Prusak, 1998), and "knowledge-centered culture" (Jackson, Chuang, Harden, \& Jiang, 2006) emphasizing the growing importance of organizational culture in the domain of KM. Cultural elements are used in various researches as influencing antecedents on various areas of knowledge management. For instance, elements of organizational culture were found to be necessary for knowledge management implementation (Mueller, 2012) and a conducive environment for knowledge creation usage (Davenport \& Prusak, 1998). Lastly, previous researchers have used the term culture as a synonym of knowledge and vice versa, (i.e., classifying culture as knowledge; a subset of knowledge and knowledge routines as part of the culture (Evans, 2012)

De Long and Fahey (2000) have discussed various circumstances in which the organizational actors may opt for knowledge hoarding rather than knowledge sharing by the inclusion of individual personalities and organizational power dynamics. Culture is classified as a control mechanism that may stimulate openness among employees and readiness to acquire knowledge values, or it may hinder the process by imposing boundaries on individuals to stay within given rules and regulations (Lee \& Cole, 2003) - acting like an enabling or hindering system in the context of knowledge management.

\section{Knowledge Vision, Trust \& Commitment, Willingness to Share and Teamwork}


Culture is known to be derived from various aspects of organizational vision that guides the values system and corresponding behaviors of employees. Bratianu and Bolisani (2015) stressed on the importance of having a knowledge vision as the source of further development of knowledge processes as the starting point in the development of a knowledge-centered organizational culture. According to them, having a knowledge vision will ensure consistency in knowledge initiatives and further practices throughout the organization. By looking deep into the particular aspect of knowledge management, we comprehend research showing that collective norms have an essential influence on the ambition of employees to share knowledge with other members of the organization (Jarvenpaa, Shaw, \& Staples, 2004). The knowledge worker, in particular, and employees, in general, use collaborative ways to share and exchange knowledge (Dyer \& Nobeoka, 2000). Not only the past research has focused on the particular values, but it also highlights the importance of trust and cooperation as a source of knowledge creation, transfer, and utilization in the organization (Delong, 2000). Here the relevance of theoretical support, which we drive from "Social Exchange Theory" makes wisdom whose fundamental focus is on exchanges resulting in trust and commitment (Cook, Cheshire, Rice, \& Nakagawa, 2013). A phenomenon well established in the case of Toyota's supplier network (Dyer \& Nobeoka, 2000). The trust which is confirmed to be a dominant concept in the knowledge management context helps in association and better collaboration among team members through the channel of commitment (Kingshott, 2006).

Team members who are willing to share encompass expert knowledge (Xue et al., 2011), which is targeted by co-members within the teams resulting in extended learning and better interaction (Rafaeli \& Raban, 2005). Nevertheless, this could only be possible when the employees have a greater feeling of sincerity for others and volunteerism to cooperate and 
collaborate. A bulk of work in the past vindicates this; for example, (Lee \& Choi, 2003) found a positive relationship between an organizational culture based on trust and learning and betterment in the knowledge processes. Similarly, Delong (2000) presented his useful work on the influence of culture on knowledge creation. His work signifies the eminence of culture on individuals and groups in perceiving, interacting, and applying knowledge for knowledge creation and distribution within the organization. By examining the key cultural elements in empirical studies, one could see the focus on trust among employees, decentralized and open values, dialogue-based communication, and shared values based on continuous improvement through risk-taking and ongoing learning. Organizational culture in a knowledge-centered organization tends to have established values and beliefs in terms of readiness to apply knowledge for change and orientation towards seeking new knowledge through practice-based learning.

Kim, Chaudhury, and Rao (2002), in their analysis of essential features for knowledge management, found eight Cs for effective knowledge management, further classifying culture as one of the most critical factors. The cultural values identified in their framework comprised of knowledge vision by top management, a vision shared adequately among employees, openness, trust among organizational members, and continuous thrust among employees for ongoing learning. They called further researchers to analyze the specific cultural values of a company (an assumption that each organization may have different cultures) to see which cultural elements fit well in the settings of the company. Evidence of such research, though limited, can be traced to the study of (Ribiere \& Sitar, 2003), who found trust, synergy, altruism, involvement, and cooperation among the employees in a knowledge-oriented culture. 
How exactly culture affects knowledge behavior? A subject of extreme interest in various studies related to knowledge management. It was revealed that best companies could embed and develop knowledge sharing capabilities through their established work routines and continuously improve these routines through learning. De Long and Fahey (2000) recognized the importance of different knowledge routines in different companies and suggested the configuration of cultural values according to these specific routines. This brings into consideration the issue of variation in knowledge routines and practices and the corresponding cultural influences for the firms. (Hong et al. (2008) indicated that to understand the overlapping relationship between culture, knowledge, routines, and capabilities (i.e., in a dynamic environmental setting), one needs to carefully analyze the link between culture and communication patterns prevailing in the organization.

Based on the thorough review of literature, we conclude that for a company looking for sustained improvement and innovation, it needs to develop a culture centered on dynamic knowledge creation to convert ideas in results. Culture drives the establishment of a framework that paves the link between organizational vision and knowledge management, which is then translated into specific objectives and goals for knowledge management (Earl, 2001). Work autonomy and motivation are factors that affect the efficiency of the processes related to knowledge creation and are also classified as essential ingredients for the transfer of tacit knowledge among employees and teams working in the organization. The influence of cultural values on organization performance may not be proven directly in some studies, but it may cast effects through indirect channels linked to management practices, human resource decisions, and various aspects relevant to organizational structure (Garavelli, Gorgoglione, \& Scozzi, 2004). The attitudes of the employees towards knowledge management are heavily influenced by the 
overall value systems prevailing in the organization, that system of values will serve as a basis of the success of a knowledge management initiative. People orientation with values of openness and risk-taking for creativity could flourish as core values in a corporate environment revolving around teams. The creation of value systems may not provide the desired results until the employees are not willing to share these values supported by management practices; a notion referred as distributed leadership will foster the essence of knowledge creation at each level of the organization and across work teams in different parts of the organization. The accomplishment of all this may require an overall reworking of the traditional culture bounded with static routines and reward systems targeting individualistic practices to models that promote agility and adaptive approach around teams that continuously engage in knowledge creation activity. Thus, we draw the following research propositions:

Proposition 1: The greater the orientation of the firm towards a knowledge culture, the greater the influence of knowledge management on organizational processes.

\section{Proposition 2: Trust, openness, dialogue-based communication and thrust for continuous}

learning will have a significant impact on the team's ability and motivation to create knowledge

In the light of the social exchange theory; work teams will have to believe in shared values, active exchange of knowledge beyond the boundaries of departments and even beyond the firm, active search for innovation as well as an open and trustworthy culture that is filled with and lived by team leaders and followers consistently. Collaboration, knowledge sharing, and continuous search for innovation is part of such a knowledge culture that could provide the right climate for a dynamic fractal organization.

\section{Leadership Role in Knowledge Creation}


A wealth of research points towards the significant role of leadership on various knowledge processes (Herman \& Mitchell, 2010; Nonaka et al., 2003), and the successful outcome of knowledge management initiatives (Kulkarni, Ravindran, \& Freeze, 2006). The role of leadership in the knowledge creation processes is often discussed in the objective realm - their ability to generate organizational memory through the transfer of tacit knowledge to explicit knowledge. Leadership is usually associated with knowledge creation process very casually; however, Nonaka in his articles on various aspects of knowledge creation and knowledge assets have suggested the importance of leadership in the creation of shared context, value judgment, utilization of requisite variety, and last but not the least in fostering practical wisdom at all levels of the organization (Nonaka et al., 2014; Nonaka \& Peltokorpi, 2006; Nonaka \& Takeuchi, 1995; Ikujiro Nonaka \& Toyama, 2007; Nonaka et al., 2003). The empirical and conceptual efforts have mostly focused on pure hard facts - predominantly focusing on knowledge management processes ignoring the critical aspect of changing context and renewal of knowledge assets. In most of these studies, leadership is seen as a central authority residing within the top ranks of the firms.

"Organizational knowledge creation is the process of making available and amplifying knowledge created by individuals, as well as crystallizing and connecting it with an organization's knowledge system" (Nonaka et al., 2000) - indicating the various leadership styles concerning the knowledge creation processes. (Yang, 2007) highlighted the prominent leadership styles of 'innovator,' 'mentor,' or 'facilitator,' in the context of knowledge management. Others have associated leadership styles with the SECI model (Andreeva \& Ikhilchik, 2011; Von Krogh et al., 2012). A growing body of literature discusses the importance of empowerment in teams that are self-managed in their decision making and practices 
(Robertson \& Swan, 2003; Sarker, Sarker, \& Schneider, 2009) and separation of leadership abilities among various levels of the organization based on "solution creation" and "operational activities" (Couillard \& Lapierre, 2003). However, recent literature indicates the rise of leadership models based on decentralized approach - a new leadership theory highlighting the importance of shared leadership abilities among team leaders and members, while they seek to create knowledge and engage in innovative projects. Thus, we draw the following proposition: Proposition 3: Leaders facilitate the knowledge creation process by developing a climate for members to share experiences.

\section{Contribution of Wise and Distributed Leadership}

The concept of wise leadership, coined by (Nonaka et al., 2014), which has a central influencing role in the knowledge creation processes and theories (Nonaka, 1994; Nonaka \& Toyama, 2007; Nonaka et al., 2003) can be an essential factor in our proposed framework. It could influence through many channels, but the focus of this study will be on two important aspects: (i) role of distributed leadership in developing suitable climate to facilitate team's ability and motivation to create knowledge and (ii) as wise leadership that has contributed in synthesizing and fostering phronesis across the teams.

The majority of studies on leadership traditionally have focused on leaders as a central authority in the organizational setting and someone who could use his influence to achieve performance and outcome from followers (Drath et al., 2008). Central leadership differs from distributed leadership as it focuses on authority, conventional power tactics, even charisma to get the work done form its followers. The outcome of collaborative effort among team members in a prevailing direction enables a sense of cooperation between members, which is the essence of the distributed leadership. As suggested by Spillane and Orlina (2005), "Leadership should be 
understood as embedded in that practice, rather than an exogenous force or an independent or intervening variable."

The role of "distributed leadership" in the knowledge creation seems obvious, i.e., to develop cultural values based on trust and vision for common understanding about knowledge management. This may result in a strong collaboration among team members and across teams as they will identify further opportunities for innovation and collective learning. Once these abilities are developed across different teams in the firm, the members could dynamically shift between various roles, i.e., leading and following (Flyvbjerg, 2001). Centralized leadership may not be able to evolve the delicate balance between this "here and now" attribute, which in our opinion convert ordinary work teams to "Dynamic Work Teams," a concept which will be elaborate in upcoming sections. Thus, we propose that:

Proposition 4: Distributed leadership will facilitate the development of dynamic teams in knowledge-creating companies.

\section{Value and Context Judgment}

This brings us to another vital pillar of knowledge management philosophy, i.e., the importance of value judgment, especially concerning the contextual setup. The objectivist approach to knowledge management distinguishes instead separates the reality from its context a context-free, value-free approach. However, in most of the social settings, leaders and team members find themselves in varying contexts demanding an analysis of beliefs, values, and influences associated with the situation (context) - context-dependent, subjective approach. Ba is now recognized as a source of making sense regarding knowledge in a given context resulting from personal interaction through time and space, resulting in new knowledge creation through constructive dialogue, sharing experiences, and transformation of information. 
In his writings, Gourlay (2006) highlights the importance of leader's belief and ability to foresee the application of specific knowledge in the context of knowledge creation, as they recognize the importance of any particular elements to be classified as knowledge evaluating the team member's ideas- a widespread practice in the development of new products. Organizational leaders, therefore, often are engaged in contextual decision making as they make decisions, they realize that most of the time, the decision variables are changing, requiring them to alter judgments and associate value propositions. They should comply with the recommendations of what is good, right, and just for the more enormous masses, i.e., "common good" (Nonaka et al., 2014). Leaders with practical wisdom demonstrate this visionary ability to see far future from the lens of teleology, value, and the following action - the essence of the phronesis.

\section{Ability to Synthesize and Foster Phronesis - Distributed Phronesis}

Another critical aspect of the dynamic fractal model revolves around the creation and sharing of practical wisdom, i.e., phronesis. There will be greater importance of the role of leadership in the synthesis of knowledge to generate practical wisdom and their ability to pass it on to team members across the organization. Nonaka has placed a strong emphasis on this type of leadership role in his previous work on "middle-top-down management" (Nonaka, 1994; Nonaka et al., 2000) and also provide clues on the notion of "Distributed Phronesis" (Nonaka et al., 2014; Von Krogh et al., 2012). For him, in order to foster innovation, corporations and leaders need to possess the "synthesizing capabilities" which are needed to integrate various pieces of knowledge and increase the quality of knowledge among members residing at all levels of the organization (Nonaka \& Von Krogh, 2009). The literature review has discussed in detail the contribution of "Wise Leaders," who can judge the best for others while taking important organizational decisions and easily understand the dynamics of a given situation spontaneously. 
The literature from the perspective of phronesis has shed light on the qualities of the "Wise Leaders" (Nonaka \& Takeuchi, 2011).

These leaders with practical wisdom can sense the consequences of actions before. They are engaged in creating shared contexts for teams and other team leaders to construct new meaning through their informal discussion in sessions. Moreover, they not only share context; instead, they also develop this essence of value and context judgment in other members of the organization via fostering the Phronetic ability in others. They can convert their experiences in exciting modes of learning mechanisms through transferring tacit knowledge for others, while traditional leaders tend to keep a distance from their followers and hide most of their wisdom and experiences. These wise leaders tend to encourage the transfer of phronesis not only in the higher ranks of the organization but also among employees and teams working in the front lines. The combination of distributed leadership and phronesis has given rise to another model of leadership, i.e., "Phronetic leadership" based on the notion that these leaders use the phronesis to achieve results in different situations. In other words, "a specific type of high-quality tacit knowledge acquired from practical experience that enables one to make prudent decisions and take action that is appropriate to each situation, guided by values and ethics" (Ikujiro Nonaka \& Toyama, 2007, p. 378). Based on our discussion, we draw the following propositions:

Proposition 5: Distributed leadership will foster practical wisdom at all levels of the knowledgecreating organization.

Proposition 6: Phronetic leadership plays a significant role in the creation of knowledge.

\section{Work Teams and Knowledge Creation}

Teams and teamwork have been one of the most promoted forms of work settings in the last few decades - an essence of the collectivist approach with a focus on mutual goals and 
benefits (Gino, Argote, Miron-Spektor, \& Todorova, 2010). A capable team has well-defined goals and the knowledge required to fulfill the targeted goals resulting in an effective way of getting the tasks done. Although organizations across the world are heavily inclined towards using teams to carry out most of the tasks, generally, all teams are not able to perform well, especially when facing changing circumstances.

Teams today face lots of challenges while establishing their knowledge routines and knowledge creation goals. Teams have a set of invisible communication relations that form the basis for their knowledge creation. Knowledge creation within teams requires sharing in an interactive setting that requires informal networks that are usually not prevalent even in most of the modern organizations (Vera \& Crossan, 2003) as these informal social ties are not systematically manageable. Nonaka's explanation of SECI facilitated by Ba explains how companies can develop and foster such ties in flexible and informal settings to configure the mechanism of a role model organization - "hypertext organizations" (Nonaka et al., 2014).

The discussion done above makes the fertile ground to discuss the setup of a hypertext organization proposed by (Nonaka \& Takeuchi, 1995), which provide knowledge workers to create organizational knowledge in various interconnected context. The hypertext organization (Nonaka \& Takeuchi, 1995) is comprised of three layers (Business layer, Project Layer, and Knowledge Layer) and the team members flexibly move in time and space (i.e., from project to business layer to knowledge layer and back) to create new knowledge while transferring their experiences and tacit knowledge in the "Knowledge base layer".

While discussing knowledge creation theory and SECI process, a vast stream of literature tends to ignore the need for improving team and individual ability (Kulkarni et al., 2006; Yang, 2007), capacity and motivation (Chen \& Cheng, 2012) to actively manage knowledge at both 
levels (Gill, 2009). The general role of leadership might be to build an environment that enhances the team's motivation for knowledge creation. However, distributed leadership could be a source of generating higher levels of motivation for dynamic knowledge creation at all levels of an organization to engender competitive knowledge (Smith, Collins, \& Clark, 2005) through fostering practical wisdom in the shape of phronesis (Nonaka et al., 2018). Knowledge creation often involves day to day interaction and collaboration among employees, and in knowledgecreating companies, the individuals realize quickly the importance of mutual benefits and cooperation, which generates a cohesive climate for collaboration (Nonaka \& Takeuchi, 1995). The notion of teamwork in flexible yet dynamic settings is entirely consistent with the model structures of knowledge creation in the shape of hierarchy (Hedlund, 1986), $\mathrm{N}$-form, or hypertext form (Nonaka, 1994). These teams not only show great motivation for knowledge creation in a flexible setting but also develop the mechanisms to reconfigure their tasks to innovate for themselves and the organizations; Drath et al. (2008) indicated similar findings in the context of cohesive work teams, where individual with their ability and motivation forgo their interest for the collective outcomes.

\section{Dynamic Work Teams (DWT) - Knowledge Creators in Fractal Organizations}

Consistent with the literature on high-performance work teams and their role in the overall knowledge management processes (Castka, Bamber, Sharp, \& Belohoubek, 2001; Solansky, 2008); we propose a new teamwork model in which capable, adaptive and agile teams are actively engaged in the knowledge creation process. We propose that such teams should be recognized as "Dynamic Work Teams (DWT)." We define dynamic work teams in the context of knowledge creation as: 
"Agile and adaptive work teams whose members are actively involved in the dynamic creation of knowledge in a work setting marked by influences from a dynamic environment."

These teams reflect the essence of effective high-performance teams similar to the ones defined by (Salamacha, Cost, Cramer, Frey, \& Glock, 2006), which they classified as "Dynamic Collaborative Action Teams" (DCAT) in the context of defense organizations, evaluating the command and control mechanism. They identified key attributes of such teams as agility, selfdefined collaboration, distributed decision making, working with other teams on related activities, rapid integration of dynamic capabilities, and strong knowledge orientation (Salamacha et al., 2006). We are classifying "dynamic work teams" based on three essential reasons. Firstly, they are, most of the time, facing problems and seeking opportunities in an environment marked by a high degree of complexity and a greater rate of change. Hence, these teams, therefore, need to be adaptive and agile enough to change their objectives and consequent processes to achieve results. Secondly, these teams are always engaged in the dynamic knowledge creation processes using the knowledge triad - explicit-tacit-phronesis conversion. Finally, the dynamic work teams using their developed flexibility shift their focus on various contexts while working on multiple projects in multiple $\mathrm{Ba}$-working in a dynamically changing context while moving in multiple layers of the organization (project, business, and knowledge) and working with different teams. Nonaka's work on knowledge-creating companies does clearly indicate the presence of such dynamic work teams in successful Japanese organizations as he integrates the working of such teams around the concept of $\mathrm{Ba}$ in the overall settings of the hypertext organization comprised of a multi-layered structure (Nonaka, 1994). Consequently, the concept of Ba becomes crucial in the context of the dynamic fractal setup as the knowledge triad is dependent on the interaction of the various dynamic teams in the network of Ba. These 
interactions are further developed both at vertical as well as the horizontal level to extend the nodes of the network which eventually becomes the central medium in the entire knowledge ecosystem (Nonaka et al., 2014).

\section{Conceptual Framework}

With the help of extensive literature, a knowledge-creating people's management framework is developed that builds around the focal elements of the dynamic fractal model. In this framework, fractals containing knowledge triad resulting in phronesis and the organization as the series of the same sphere residing at each level of the organization (Figure 5). This happens in a multi-layered shared context supporting the simultaneous occurrence of exploration and exploitations, enabling teams to achieve innovation goals.

The framework depicts the importance of a leader in the context of knowledge management, nurturing interactions, and communication between team players by instilling an atmosphere that cares about the team members through values based on trust and a shared space for the team to create and transfer knowledge to others. This model takes the lead form the work of various authors on the role of wiser leaders - the distributed practical wisdom (Nonaka \& Takeuchi, 2011; Nonaka \& Toyama, 2007).

Phronesis resulting from the knowledge triad, instead of being static, is determined by the context and is systematically distributed in the firms since effective knowledge management would require the active commitment of every individual in the organization. The importance of the invisible sphere (a single fractal), i.e., the knowledge triad, is highlighted as the networks of Ba support it for the synthesizing process in a simultaneous occurrence of exploration and exploitation for dynamically creating upward spiral for new knowledge creation. This process involves various actors and organizations to extend the various Ba horizontally and vertically, 


\section{***Insert Figure 5 about here $* * *$}

which in turn dynamically reconfigure the interaction between the various actors within and across the organizations to establish the knowledge ecosystem holistically.

We are integrating knowledge management with constructs from organizational behavior to find linkages between employee's management and the fractal organizational model. We propose that organizational culture will have a central role in driving this knowledge management framework based on the dynamic fractal model. It will be enabling an essential stream of influence that could foster and facilitate the knowledge creation process (Wang \& Huang, 2009).

The knowledge-oriented companies tend to have a shared culture that has a mediating impact on the whole setting, especially when the organizations are looking forward to incorporating dynamic routines. The robust value system would then play the role of a positive influencer, as suggested by (Bryant, 2003). This is where the present study holds its contribution by examining the need for a change in traditional knowledge-based cultural routines that are focusing on codification strategy towards a new organizational culture where a more distributed leadership style is being encouraged with focus on values such as teamwork, commitment to the knowledge vision and collaboration based on trust and willingness to share (Hawkins, 2017; Xue et al., 2011). We suggest that the construction of settings around dynamic knowledge creation mechanisms requires a precise knowledge vision, which gives a direction to knowledge creation. "It also gives the firm direction with respect to the knowledge to be created beyond the firms' existing capabilities and therefore determines how the firm evolves in the long run" (Nonaka \& Toyama, 2007, p. 18). 
The cultural values identified in the literature could be used to develop a cohesive climate for dynamic teams to not only prosper but also actively engage in dynamic knowledge creation. This enriched team climate acts as a robust collaborative mechanism for dynamic teams, while team leaders act in the role of coordinator and facilitator and increase team members' motivation through the essence of distributed leadership. We can recall various case studies on Japanese firms discussed in the literature (Ikujiro Nonaka \& Takeuchi, 1995, 2011; Ikujiro Nonaka \& Toyama, 2007) where leaders of successful companies were able to provide ample space for knowledge workers in various teams in multiple Ba (physical and virtual) thus enabling active teamwork and organize social events. The organization and its knowledge actors have a dynamic role in the relationship with the environment with an ability to influence the setting through their knowledge-creating ability (Ikujiro Nonaka \& Toyama, 2003). Dynamic teams will drive the knowledge creation process using the knowledge triad, developing synthesizing capabilities in the daily routines, and interacting through the network of multi-layered $\mathrm{Ba}$. A combination of dynamic knowledge creation through work teams supported by distributed leadership in the fractal structure will eventually foster long-lasting innovation because the process will occur on a higher level of the knowledge creation spiral - a model seems most applicable in highly dynamic conditions.

\section{Research Methodology}

The propositions discussed in the study combines multiple areas of research, including teams, knowledge management, leadership, and innovation within DFOs. The objective was to develop a theory using these propositions. Thus, we employed a qualitative case study method to examine our propositions. Case studies are well-suited for research problems that are in the preliminary stages of investigation with no prior empirical evidence (Scholz \& Tietje, 2002; Yin, 
1994). Case studies can explore, describe, and explain the case of interest and enable in-depth, meaningful, and context-constituted knowledge and understanding about real-life events (Luck, Jackson, \& Usher, 2006). Especially when the research problem is new and emerging, the qualitative case study method becomes a useful tool to simplify the understanding of the complex phenomenon (Luck et al., 2006). We collected data using multiple methods, including 24 in-depth interviews (project managers, human resource specialists, App developers, marketing and policy specialists), group discussions, personal observations, and document analysis. Collecting data from multiple sources helped to generate and triangulate a comprehensive analysis of the complex processes and knowledge creation activities (Yin, 1994).

We studied GenITeams, a leading Pakistani software company, as our case for this study. The first author initially visited the organization to understand the context of this organization and gain necessary approvals for the study. We first contacted the human resource manager of GenITeams and discussed our proposed study. The manager then scheduled our meeting with the top management to discuss our study objectives and protocols. The management and the study participants were ensured about their confidentiality and voluntary participation in the study. The human resource manager served as a liaison between our research teams and study participants.

GenITeams is a Pakistan based startup, established in November 2007 (http://www.GenITeams.com), which specializes in mobile application development. It has gradually expanded from a local customer base to a global provider for mobile applications and games developer, working on global assignment with 50 million-plus user base across all possible mobile platforms. Red Hiring innovation magazine ranked GenITeams among the top 100 innovative companies in Asia in 2012. Thus, a vibrant company with global exposure provided us excellent settings to fulfill our research objectives. 


\section{Qualitative Case Study: Dynamic Knowledge Creation within Vibrant Teams at}

\section{GenITeams}

GenITeams is a trusted partner of best mobile studios across the world. The company's vision is to mark the presence in the niche segment of mobile development, widely anticipated as the technological solution for the new generation. Frequent environmental changes, the intensity of competition, and the expansion of a wide range of products are challenging the ideology and functioning of the modern app development industry. The future of the industry may unfold attractive opportunities for competing companies, especially in the area of knowledge creation and utilization (Akhavan, Ebrahim, Fetrati, \& Pezeshkan, 2016). Knowledge-Intensive Firms are preliminarily defined as "organizations that offer markets the use of fairly sophisticated knowledge or knowledge-based products" (Alvesson, 2004, p. 17). So an app development firm could be classified as knowledge-intensive work units as it correlates with the above definition quite easily. Knowledge-intensive processes such as research and development, customer support services, and, most crucial organizational knowledge and competences management are crucial aspects of modern app development firms. The success of app development firms largely depends on their ability to seek opportunities to reinvent their products innovatively and shift to new models that foster enriched and revitalized knowledge stocks.

Initially, the company offered its development services for mobile apps, i.e., both android and ios; and the continuous innovation led the company to enter 2D and 3D gaming products. The company holds a diverse portfolio in mobile applications and games that include working for UAE Government (For example, My Genie, Etisalat Yellow Pages, Angry Monkey, Track my Train, and Trucker Parking 3D). GenITeams follows the "Agile" app development approach (Martin, 2002), where the development process ensures high involvement of participants and 
development teams resulting in improved quality. The agile development process is divided into three stages, i.e., Pre-Production, Production, and Post-Production.

$$
* * * \text { Insert Figure } 6 \text { about here*** }
$$

The revolution in the App development industry is marked by the fact that most of the clients now recognize the importance of knowledge creation potential while targeting firms rather than focusing on just problem-solving aspects. This has challenging implications for app development firms as they now have to focus beyond targeting the exchange of standardized explicit knowledge sets and seek potential in more tacit knowledge elements. The app development companies need to realize the potential in approaches and opportunities for exploring and synthesizing knowledge creation activities throughout their network of stakeholders. Once we look at the type of knowledge associated with app development firms, the explicit knowledge is just the apparent element which has its strong roots in the tacit knowledge. The knowledge creation process requires capitalizing on the more enriched forms of knowledge (the experiences) - a potential focus on "phronesis." The various teams working in these firms could be transferred in dynamic work teams to generate phronesis (practical wisdom) that requires dynamic integration of resources while sharing experiences in multiple Ba. The problem-solving routines could result in new knowledge creation as the focus will remain on the usage of constructive dialogues and purposeful criticism within and across teams to find innovative solutions to client's problems. These teams could bring a variety of complementary skills in many areas to improve idea generation by facilitating the ongoing conversion of basic knowledge to phronesis with simultaneous occurrence of knowledge exploration and exploitation that will continuously renew the overall organizational knowledge potential. 
DFO, as a management model, requires a reworked internal climate based on vision, trust, commitment, willingness to share, and teamwork. GenITeamss proved to be a workplace with a clear focus on knowledge creation as a source of innovation by reconfiguring itself to develop and facilitate the dynamic knowledge-creating teams. This echoes with Tsoukas (1996) proposed a framework where firms could adjust themselves as a team-based setup and continuously evolve their knowledge-creating mechanisms with the dynamic and continuous reconfiguration of their boundaries. Although GenITeamss may not be a perfect match for all ingredients in the proposed framework in this article, yet it has many features that provide clues to essential aspects of a modern knowledge-creating firm. With a reliable structure-based management approach, knowledge creation mechanism support teams at the different projects to integrate resources and innovate with acceleration. Table 1 presents the division wise classification of the company in Table 1.

***Insert Table 1 about here***

While most of the app development firms have a set structure based on hierarchies, the DFO model based on dynamic teams could still be a suitable mechanism for knowledge creation in so many ways. While structured elements enable firms to organize around the multi-layered $\mathrm{Ba}$, the dynamic teams working in Ba provide for the dynamism and flexibility required in coping with the dynamic environment. The DFO based people management model would translate essential knowledge management abilities to teams working in the front lines; especially, team workers working at the operational level. As Ikujiro Nonaka et al. $(2014$, p. 7) suggested: "In this way, the knowledge triad relationships can be observed both within the structured organizations as well as within the dynamic organization systems in a company, in between organizations, and across the boundaries of the companies and their environment." The team could make it a habit, and the knowledge-creating fractal could be translated as established 
routines in daily work practices, resulting in innovation at each level in a systematic yet flexible way.

In today's knowledge-based economy, innovation is a must for sustainable growth. Knowledge creation at GenITeams is not restricted to individuals; instead, it is designed around collective efforts linking multiple actors at different levels. As one of the project team leaders quoted:

"In order to transfer knowledge from explicit to other forms, we need to start with the social factors, i.e., starting the process by making individuals conscious of the importance and benefits of sharing their knowledge."

The CEO of GenITeams also highlighted the value of having a knowledge management focus when he talked about the importance of having a knowledge vision and sharing:

"One of the most common visions that organizations promote is "Knowledge is Power," and in our company, individuals are required to see their experience and unique knowledge as a "power capital" that give them acknowledgment inside the organizations and increase their selfesteem."

During the various stages of projects, i.e., Idea Selection, Storyboarding, Designing, Development, and Post-production, teams are involved in various knowledge creation processes. When brilliant ideas emerge, the team members make sure that they evaluate the idea for practical acceptability. Customers and critical team members keep in constant touch during the stage of storyboarding with your app/game developer, and all stakeholders are engaged in an ongoing feedback loop. When the project enters the designing phase, users are attracted to visual aspects and come in close coordination with the team members to provide feedback and evaluate multiple aspects of the app. After multiple trials and finalization of the various aspects of the 
app, especially moving through the quality assurance process, the development phase is concluded. Marketing teams take over from this point and ensure that the app catches the attention of the market. Social media and online tools are used in this phase to capture local and international players.

\section{Discussion and Conclusion}

In this paper, we have analyzed the new type of people's management model through the support of distributed leadership and cultural values system comprising of knowledge vision, trust, commitment, teamwork, and sharing among team members. We propose that such an environment will encourage the team to actively engage in the knowledge creation processes using the knowledge triad. We have tried to explore sources of innovation in firms using the people's management metaphor and have proposed the framework that, in our opinion, could provide knowledge leaders and activists a mechanism they could adopt to yield sustainable innovation. The emphasis on collaboration, complementarity with a shared knowledge vision will drive the teams towards a dynamic work unit with an ability to synthesize different types of knowledge - a novel people's management approach that promises benefits of continuous renewal of knowledge and multiplied innovative opportunities. These teams do not emerge informally; instead, the organizational climate systematically generates shared context and collaborative knowledge creation routines that enable these to create knowledge more dynamically than any other static work entity. Ideally, both intra-team and inter-team relationships will be based on multi-layered network $\mathrm{Ba}$ and will demonstrate open communication and actively shared goals, values, and beliefs.

The dynamic fractal organization, when seen from the people's management lens, promises to be a potential organizational model with four essential dimensions of people's 
management: (i) cultural values suited for dynamic teams in DFO, (ii) role of distributed leadership - as an ideal model of management, (iii) development of future knowledge-intensive work around dynamic teams, and (iv) dynamic and flexible progression of knowledge-creating teams in a fractal structure. By doing so, we contribute to the field of organization theory (OT) as our model presents a novel way to examine the management of organizations facing dynamic environmental influences. Leaders will play their role in fostering knowledge vision and in establishing the right mix of cultural values for the dynamic fractal organizations. The knowledge triad (explicit, tacit, and phronesis) remains the primary focus for the dynamic team's management and enables fostering of phronesis within teams at every level of the organization. To put our propositions in a context, we have evaluated an App development firm GenITeamss as a case study to examine the scope of the implementation of the proposed conceptual model. The company is more focused on agile methodology; therefore, the process ensures high involvement of stakeholders and hence results in higher game/app quality. This generally starts with the sharing of basic knowledge to significant stakeholders, and from there information is cycled as workable solutions based on individual and expert experiences/events. Tacit knowledge hence serves as the basis for execution and even after it serves as a knowledge hub for future executions of the company.

GenITeams considers inducing strong cultural and knowledge-oriented values to a new employee during his early days of induction in the company. Employees start with a detailed HR orientation that leads to division level discussions and technical training programs in the initial month. The critical aspect of the initial training is acquaintance with the company knowledge base and knowledge-based communities offering peer assistance during project implementation phases. Detailed retrospect meetings are conducted regularly to find answers to critical questions 
related to employee's learning during the knowledge creation processes. Use of Project Management tool, i.e., Assembla, also helps to formalize every single event and process that is ongoing or has been finished in the past. It serves as a database for new inductees and top management to make future choices. Learning through blogs is considered a key area of knowledge management in recent days; therefore, the company introduced a blog (www.blogs.GenITeams.com) to incorporate the learning of new employees through experiences of employees already working on critical projects.

It is difficult for the experts to document their knowledge because it is already embedded in their minds, and in most cases, some of them do not even know how they do it; they just keep on doing things naturally. At GenITeamss, a knowledge observer is appointed that interact with team members and track the experts thinking process by observing and documenting these knowledge activities. Informal discussions and constant observation have become a significant source of tacit knowledge management. One of the most critical factors for tacit knowledge transfer is trust, and to ensure knowledge workers are motivated to share their knowledge, GenITeams maintains an influential culture of trust. GenITeams started developing communities of practice - the socialization $\mathrm{Ba}$. This resulted in the socialization of team members, mostly in informal settings encouraging knowledge sharing and idea generation.

The HR Manager indicated the importance of the socialization process through experts with greater wisdom in two ways as he quoted:

"Team members use this socialization for dual purpose, i.e., for their benefit and as an altruistic act of supporting their colleagues; the resulting values create an environment of mutual support during the app development processes."

\section{The implication for Practitioners and Future Directions}


Knowledge is created by individuals who have their perception of reality and is also embedded in their actions in a given context - an explanation valid for individuals, teams, and organizations alike (Ikujiro Nonaka et al., 2000). If a firm is a collection of teams, the knowledge stock resides with these people in a collective setting and could be classified as organizational knowledge. Unless these groups and teams communicate and socialize in a shared space such as Ba (Ikujiro Nonaka et al., 2014), organizational knowledge will remain underutilized in fragmented groups. Practitioners need to develop such conclusive environments for interaction to take place physically or virtually. Knowledge sharing is facilitated through SECI (Ikujiro Nonaka et al., 2000), and the tacit knowledge sharing process, in particular, requires cohesive linkages between multiple organizational teams. Following Nonaka's suggestion, we believe that knowledge needs a strong cohesive environment based on trust and willingness to share (a set off characteristics found in famous Japanese firms) within the whole organization.

The importance of culture as a source of enabling and facilitating climate indicates a more substantial implication for leadership in the dynamic knowledge-based organizations. Leaders need to recognize the importance of cultural change in the context of new knowledge creation models. Moreover, success for knowledge-intensive firms lies in the strength of their knowledge creation that is embedded in the contradiction of opinions and constructive dialogues between dynamic teams within the network of Ba. This duality of thoughts becomes a source of synthesis and creation of reality, which in its philosophical position differs totally from binary thinking. In other words, dynamic team members would use a knowledge triad with synthesizing ability in the multi-layered fractal settings at almost all levels of the organization. This requires changes like jobs, team objectives, shared routines, and approaching opportunities and problems 
in a collective approach. Teams facing dynamic environments will have to ensure adequate knowledge creation processes with a focus on constructive dialogue to yield innovative opportunities throughout the organization.

We acknowledge the limitations of this research as it confirms some aspects of the framework proposed based on a single case study. Therefore, we recommend future research in the following areas. First, we suggest that scholars should conduct empirical research to test the strength of the model in various contexts, including the manufacturing and services sectors.

Second, we did not consider the significance of institutional effects within the proposed framework. Thus, Institutional effects need further exploration, such as the type of organizational structure (highly structured versus decentralized firms) and its effect on knowledge creation within teams.

\section{References}

Akhavan, P., Ebrahim, N. A., Fetrati, M. A., \& Pezeshkan, A. (2016). Major trends in knowledge management research: a bibliometric study. Scientometrics, 107(3), 1249-1264.

Alvesson, M. (2004). Knowledge work and knowledge-intensive firms: OUP Oxford.

Andreeva, T., \& Ikhilchik, I. (2011). Applicability of the SECI model of knowledge creation in Russian cultural context: theoretical analysis. Knowledge and process management, 18(1), 56-66.

Argote, L. (2012). Organizational learning: Creating, retaining and transferring knowledge: Springer Science \& Business Media.

Batsakidis, A., \& Tsigkas, A. (2019). Practical wisdom in a complex world: building the resilient supply chain. International Journal of Supply Chain and Operations Resilience, 3(4), 353368. doi: 10.1504/ijscor.2019.099468

Beuter Júnior, N., Faccin, K., Volkmer Martins, B., \& Balestrin, A. (2019). Knowledge-Based Dynamic Capabilities for Sustainable Innovation: The Case of the Green Plastic Project. Sustainability, 11(8), 2392. 
Bouwman, R., \& Brohm, R. (2016). Phronetic judgement, an essential competence for a project manager in a complex project environment! International Journal of Business and Globalisation, 17(4), 582-596. doi: 10.1504/ijbg.2016.079341

Bratianu, C., \& Bolisani, E. (2015). Knowledge strategy: An integrated approach for managing uncertainty. Paper presented at the Proceedings of the 16th European conference on Knowledge Management.

Bryant, S. E. (2003). The role of transformational and transactional leadership in creating, sharing and exploiting organizational knowledge. Journal of Leadership \& Organizational Studies, 9(4), 32-44.

Castka, P., Bamber, C., Sharp, J., \& Belohoubek, P. (2001). Factors affecting successful implementation of high performance teams. Team Performance Management: An International Journal, 7(7/8), 123-134.

Chen, S.-H. (2016). The influencing factors of enterprise sustainable innovation: an empirical study. Sustainability, 8(5), 425.

Chen, W.-J., \& Cheng, H.-Y. (2012). Factors affecting the knowledge sharing attitude of hotel service personnel. International Journal of Hospitality Management, 31(2), 468-476.

Chuang, C.-H., Jackson, S. E., \& Jiang, Y. (2016). Can knowledge-intensive teamwork be managed? Examining the roles of HRM systems, leadership, and tacit knowledge. Journal of management, 42(2), 524-554.

Cook, K. S., Cheshire, C., Rice, E. R., \& Nakagawa, S. (2013). Social exchange theory Handbook of social psychology (pp. 61-88): Springer.

Couillard, D., \& Lapierre, J. (2003). Leadership, learning and resources for the high-tech firm: an integrated view of technology management. International Journal of Technology Management, 26(7), 767-787.

Davenport, T. H., \& Prusak, L. (1998). Working knowledge: How organizations manage what they know: Harvard Business Press.

De Long, D. W., \& Fahey, L. (2000). Diagnosing cultural barriers to knowledge management. Academy of Management Perspectives, 14(4), 113-127.

Delong, D. (2000). Fahey, 2000. Diagnosing Cultural Barriers to Knowledge. Management. Academy of Management Executive, 14, 113-127. 
Drath, W. H., McCauley, C. D., Palus, C. J., Van Velsor, E., O'Connor, P. M., \& McGuire, J. B. (2008). Direction, alignment, commitment: Toward a more integrative ontology of leadership. The leadership quarterly, 19(6), 635-653.

Dyer, J. H., \& Nobeoka, K. (2000). Creating and managing a high-performance knowledge-sharing network: the Toyota case. Strategic Management Journal, 21(3), 345-367.

Earl, M. (2001). Knowledge management strategies: Toward a taxonomy. Journal of Management Information Systems, 18(1), 215-233.

Ervas, F., \& Gola, E. (2016). Arguing by metaphors. Rivista Italiana di Filosofia del Linguaggio, 10(2).

Evans, N. (2012). Destroying collaboration and knowledge sharing in the workplace: a reverse brainstorming approach. Knowledge Management Research \& Practice, 10(2), 175-187.

Fernández-Martínez, M., \& Sánchez-Granero, M. (2016). A new fractal dimension for curves based on fractal structures. Topology and its Applications, 203, 108-124.

Flyvbjerg, B. (2001). Making social science matter: Why social inquiry fails and how it can succeed again: Cambridge university press.

Garavelli, C., Gorgoglione, M., \& Scozzi, B. (2004). Knowledge management strategy and organization: A perspective of analysis. Knowledge and process management, 11(4), 273282.

Gill, A. (2009). Knowledge management initiatives at a small university. International Journal of Educational Management, 23(7), 604-616.

Gino, F., Argote, L., Miron-Spektor, E., \& Todorova, G. (2010). First, get your feet wet: The effects of learning from direct and indirect experience on team creativity. Organizational Behavior and Human Decision Processes, 111(2), 102-115.

Gloet, M., \& Samson, D. (2020). Knowledge management and systematic innovation capability Disruptive Technology: Concepts, Methodologies, Tools, and Applications (pp. 11981218): IGI Global.

Gourlay, S. (2006). Towards conceptual clarity for 'tacit knowledge': a review of empirical studies. Knowledge Management Research \& Practice, 4(1), 60-69.

Hackman, J. R., \& Katz, N. (2010). Group behavior and performance. Handbook of social psychology, 2, 1208-1251. 
Hawkins, P. (2017). Leadership team coaching: Developing collective transformational leadership: Kogan Page Publishers.

Hedlund, G. (1986). The hypermodern MNC - a heterarchy? Human resource management, 25(1), 9-35.

Herman, H., \& Mitchell, R. J. (2010). A theoretical model of transformational leadership and knowledge creation: The role of open-mindedness norms and leader-member exchange. Journal of Management \& Organization, 16(1), 83-99.

Hong, H. K., Kim, J. S., Kim, T., \& Leem, B. H. (2008). The effect of knowledge on system integration project performance. Industrial Management \& Data Systems.

Huckman, R. S., \& Staats, B. R. (2011). Fluid tasks and fluid teams: The impact of diversity in experience and team familiarity on team performance. Manufacturing \& Service Operations Management, 13(3), 310-328.

Huckman, R. S., Staats, B. R., \& Upton, D. M. (2009). Team familiarity, role experience, and performance: Evidence from Indian software services. Management science, 55(1), 85100.

Jackson, S. E., Chuang, C.-H., Harden, E. E., \& Jiang, Y. (2006). Toward developing human resource management systems for knowledge-intensive teamwork Research in personnel and human resources management (pp. 27-70): Emerald Group Publishing Limited.

Jakubik, M. (2008). Experiencing collaborative knowledge creation processes. The Learning Organization, 15(1), 5-25.

Jarvenpaa, S. L., Shaw, T. R., \& Staples, D. S. (2004). Toward contextualized theories of trust: The role of trust in global virtual teams. Information Systems Research, 15(3), 250-267.

Jeng, D. J.-F., \& Dunk, N. (2013). Knowledge management enablers and knowledge creation in ERP system success. International Journal of Electronic Business Management, 11(1), 49.

Kim, Y. J., Chaudhury, A., \& Rao, H. R. (2002). A knowledge management perspective to evaluation of enterprise information portals. Knowledge and process management, 9(2), $57-71$.

Kingshott, R. P. (2006). The impact of psychological contracts upon trust and commitment within supplier-buyer relationships: A social exchange view. Industrial Marketing Management, 35(6), 724-739. 
Kuhn, T. S., \& Ortony, A. (1979). Metaphor and thought. by Andrew Ortony. Cambridge: Cambridge University Press. Chap. Metaphor in Science, 409-419.

Kulkarni, U. R., Ravindran, S., \& Freeze, R. (2006). A knowledge management success model: Theoretical development and empirical validation. Journal of Management Information Systems, 23(3), 309-347.

Lee, G. K., \& Cole, R. E. (2003). From a firm-based to a community-based model of knowledge creation: The case of the Linux kernel development. Organization science, 14(6), 633-649.

Lee, H., \& Choi, B. (2003). Knowledge management enablers, processes, and organizational performance: An integrative view and empirical examination. Journal of Management Information Systems, 20(1), 179-228.

Luck, L., Jackson, D., \& Usher, K. (2006). Case study: a bridge across the paradigms. Nursing inquiry, 13(2), 103-109.

Marlien, R., Maskur, A., \& Setiawan, M. (2016). Effectiveness Analysis Capabilities Sales Personnel on Value Co-creation. Proceeding ICOBAME.

Martin, R. C. (2002). Agile software development: principles, patterns, and practices: Prentice Hall.

Mikhail, O., Marina, I., \& Vitaly, I. (2017, 2017/05). The Fractal Nature of Implicit Knowledge. Paper presented at the 3rd International Conference on Arts, Design and Contemporary Education (ICADCE 2017).

Mueller, J. (2012). Knowledge sharing between project teams and its cultural antecedents. Journal of Knowledge Management, 16(3), 435-447.

Nikbakht, M. (2017). Radiative heat transfer in fractal structures. Physical Review B, 96(12), 125436.

Nonaka, I. (1994). A dynamic theory of organizational knowledge creation. Organization science, 5(1), 14-37.

Nonaka, I., Hirose, A., \& Takeda, Y. (2016). 'Meso'-Foundations of Dynamic Capabilities: TeamLevel Synthesis and Distributed Leadership as the Source of Dynamic Creativity. Global Strategy Journal, 6(3), 168-182.

Nonaka, I., Kodama, M., Hirose, A., \& Kohlbacher, F. (2014). Dynamic fractal organizations for promoting knowledge-based transformation-A new paradigm for organizational theory. European Management Journal, 32(1), 137-146. 
Nonaka, I., Nishihara, A. H., \& Kawada, H. (2018). Knowledge-Based Management Theory. In A. Hirose Nishihara, M. Matsunaga, I. Nonaka \& K. Yokomichi (Eds.), Knowledge Creation in Public Administrations: Innovative Government in Southeast Asia and Japan (pp. 1-21). Cham: Springer International Publishing.

Nonaka, I., \& Peltokorpi, V. (2006). Objectivity and subjectivity in knowledge management: a review of 20 top articles. Knowledge and process management, 13(2), 73-82.

Nonaka, I., \& Takeuchi, H. (1995). The knowledge-creating company: How Japanese companies create the dynamics of innovation: Oxford university press.

Nonaka, I., \& Takeuchi, H. (2011). The wise leader. Harvard business review, 89(5), 58-67, 146.

Nonaka, I., \& Toyama, R. (2003). The knowledge-creating theory revisited: knowledge creation as a synthesizing process. Knowledge Management Research \& Practice, 1(1), 2-10. doi: 10.1057/palgrave.kmrp.8500001

Nonaka, I., \& Toyama, R. (2007). Why do firms differ? The theory of the knowledge-creating firm. Knowledge creation and management. New challenges for managers, 13-31.

Nonaka, I., Toyama, R., \& Byosiere, P. (2003). A Theory of Knowledge Creation. The knowledgecreating.

Nonaka, I., Toyama, R., \& Konno, N. (2000). SECI, Ba and leadership: a unified model of dynamic knowledge creation. Long Range Planning, 33(1), 5-34.

Nonaka, I., \& Von Krogh, G. (2009). Perspective-Tacit knowledge and knowledge conversion: Controversy and advancement in organizational knowledge creation theory. Organization science, 20(3), 635-652.

Pässilä, A., Uotila, T., \& Melkas, H. (2013). Facilitating future-oriented collaborative knowledge creation by using artistic organizational innovation methods: Experiences from a Finnish wood-processing company. Futures, 47, 59-68. doi: https://doi.org/10.1016/j.futures.2013.01.003

Rafaeli, S., \& Raban, D. R. (2005). Information sharing online: a research challenge. Available at SSRN 999993.

Ribiere, V. M., \& Sitar, A. S. (2003). Critical role of leadership in nurturing a knowledgesupporting culture. Knowledge Management Research \& Practice, 1(1), 39-48.

Robertson, M., \& Swan, J. (2003). 'Control-what control?'Culture and ambiguity within a knowledge intensive firm. Journal of management Studies, 40(4), 831-858. 
Rynes, S., \& Gephart Jr, R. P. (2004). From the Editors: Qualitative Research and the" Academy of Management Journal". The Academy of Management Journal, 454-462.

Salamacha, C. O., Cost, R. S., Cramer, M., Frey, T., \& Glock, D. P. (2006). Dynamic collaborative action teams: Implementing a transformational concept. Paper presented at the Proceedings of Command and Control Research and Technology Symposium (CCRTS 06).

Sarker, S., Sarker, S., \& Schneider, C. (2009). Seeing remote team members as leaders: A study of US-Scandinavian teams. IEEE Transactions on professional communication, 52(1), 7594.

Scalzo, G. R. (2019). Aristotelian phronesis as a key factor for leadership in the knowledgecreating company according to Ikujiro Nonaka. OPENAIRE.

Scholz, R. W., \& Tietje, O. (2002). Types of case studies. Embedded case study methods, 9-14.

Seetharaman, A., Saravanan, A. S., Patwa, N., Niranjan, I., Jadhav, V., \& Porkodi, V. P. (2019). Impact of knowledge sharing on virtual team projects. International Journal of Knowledge Management Studies, 10(4), 337-364. doi: 10.1504/ijkms.2019.103354

Smith, K. G., Collins, C. J., \& Clark, K. D. (2005). Existing knowledge, knowledge creation capability, and the rate of new product introduction in high-technology firms. Academy of management journal, 48(2), 346-357.

Solansky, S. T. (2008). Leadership style and team processes in self-managed teams. Journal of Leadership \& Organizational Studies, 14(4), 332-341.

Song, J. H. (2008). The effects of learning organization culture on the practices of human knowledge-creation: an empirical research study in Korea. International Journal of Training and Development, 12(4), 265-281.

Song, J. H., \& Chermack, T. J. (2008). A theoretical approach to the organizational knowledge formation process: Integrating the concepts of individual learning and learning organization culture. Human Resource Development Review, 7(4), 424-442.

Spillane, J. P., \& Orlina, E. C. (2005). Investigating leadership practice: Exploring the entailments of taking a distributed perspective. Leadership and Policy in Schools, 4(3), 157-176.

Tan, Y. H., \& Tan, S. C. (2020a). Understanding Knowledge Creation. In Y. H. Tan \& S. C. Tan (Eds.), Conceptions of Knowledge Creation, Knowledge and Knowing: A 
Phenomenography of Singapore Chinese Language Teachers (pp. 13-33). Singapore: Springer Singapore.

Tan, Y. H., \& Tan, S. C. (2020b). Understanding Knowledge Creation Conceptions of Knowledge Creation, Knowledge and Knowing (pp. 13-33): Springer.

Tsoukas, H. (1996). The firm as a distributed knowledge system: A constructionist approach. Strategic Management Journal, 17(S2), 11-25.

Vera, D., \& Crossan, M. (2003). Organizational learning and knowledge management: Toward an integrative framework. The Blackwell handbook of organizational learning and knowledge management, 122-142.

Von Krogh, G., Nonaka, I., \& Rechsteiner, L. (2012). Leadership in organizational knowledge creation: A review and framework. Journal of management Studies, 49(1), 240-277. doi: doi.org/10.1111/j.1467-6486.2010.00978.x

Wang, Y.-S., \& Huang, T.-C. (2009). The relationship of transformational leadership with group cohesiveness and emotional intelligence. Social Behavior and Personality: An International Journal, 37(3), 379-392.

Xue, Y., Bradley, J., \& Liang, H. (2011). Team climate, empowering leadership, and knowledge sharing. Journal of Knowledge Management, 15(2), 299-312.

Yang, J.-T. (2007). Knowledge sharing: Investigating appropriate leadership roles and collaborative culture. Tourism Management, 28(2), 530-543.

Yin, R. K. (1994). Case study research: design and methods. Applied social research methods series, 5. Biography, Sage Publications, London.

Zárraga, C., \& Bonache, J. (2003). Assessing the team environment for knowledge sharing: an empirical analysis. International Journal of Human Resource Management, 14(7), 12271245. 


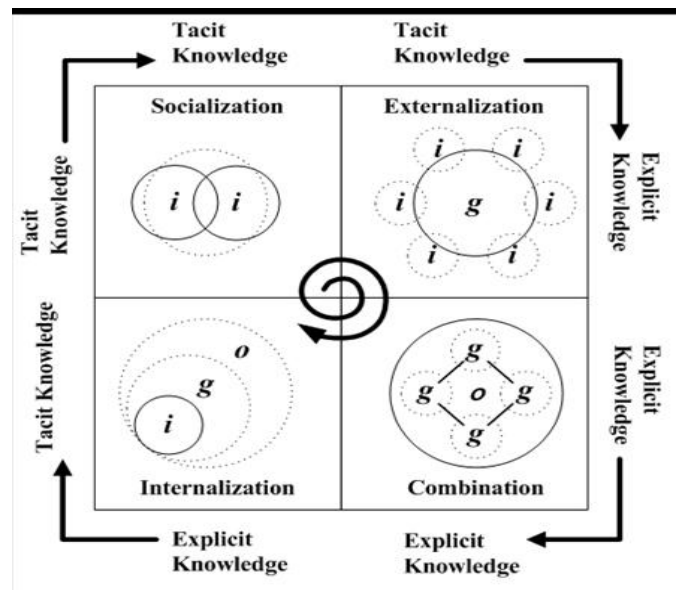

Figure 1. SECI Model

Source: Nonaka et al., 2000

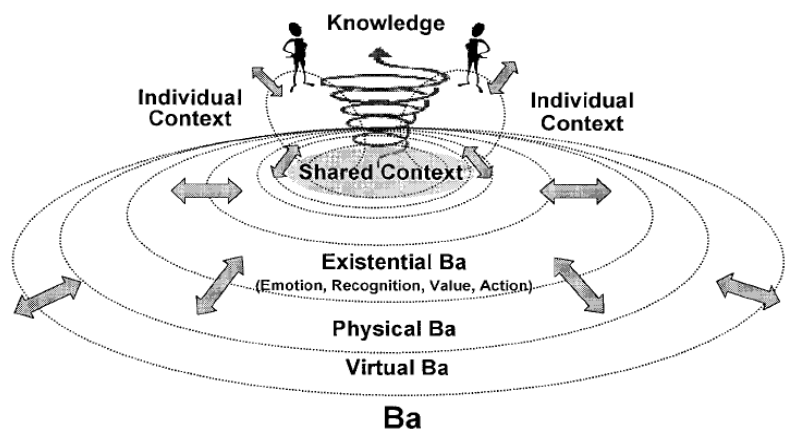

Figure 2. Conceptual representation of $\mathrm{Ba}$

Source: Nonaka et al., 2003, p. 7 


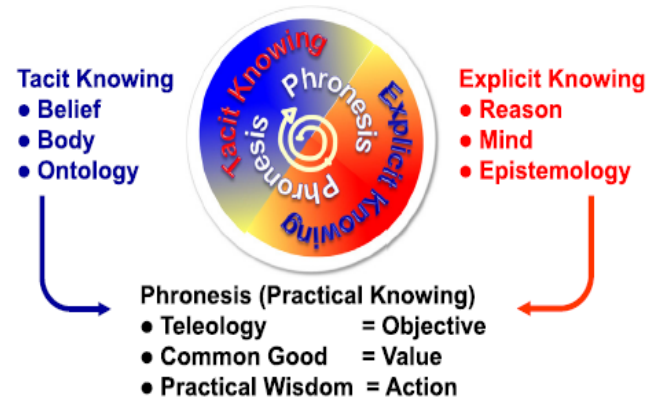

Figure 3. Conceptualization of the Knowledge Triad

Source: Nonaka et al., 2014, p. 139

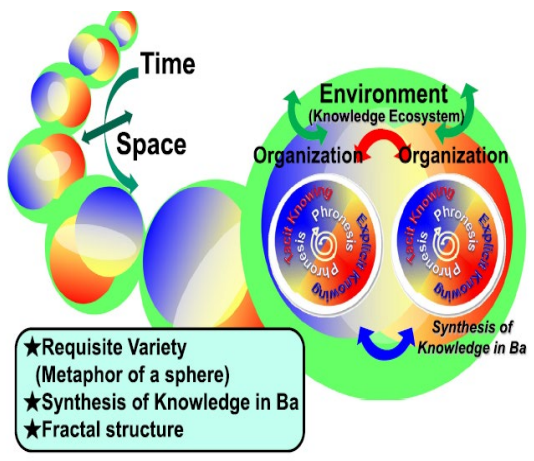

Figure 4. Dynamic Fractal Organization

Source: Nonaka et al., 2014, p. 141 


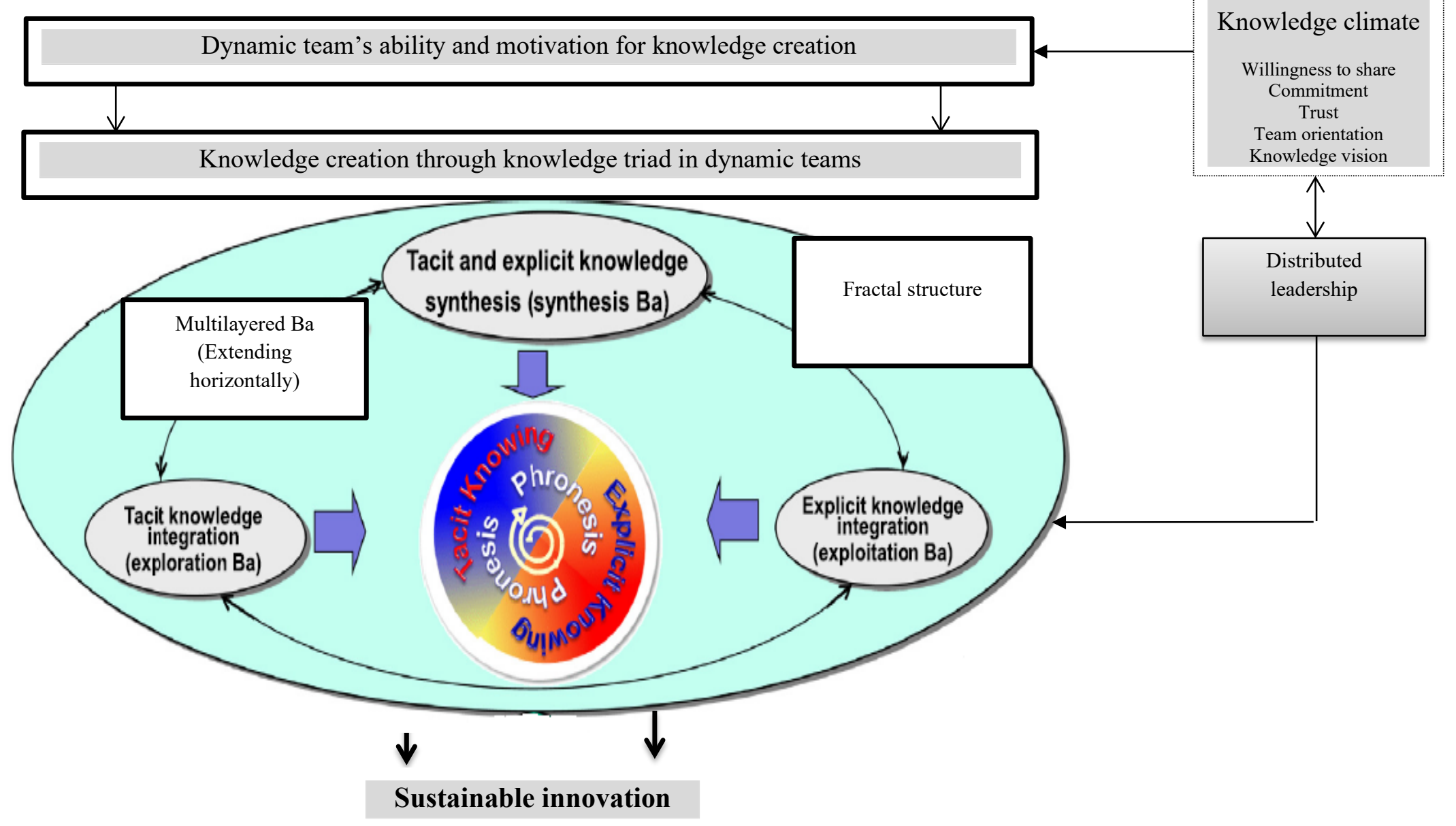

Figure 5. A Model of Sustained Innovation through Dynamic Teams in Dynamic Fractal Organizations 


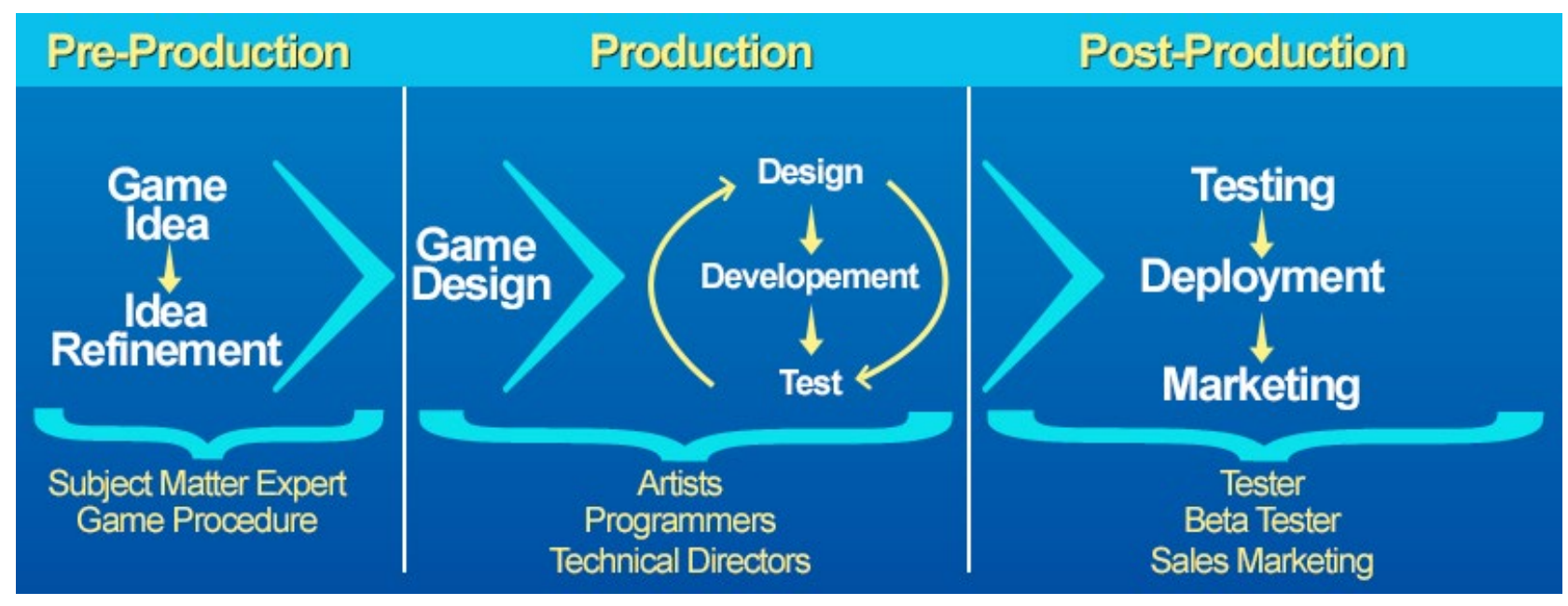

Figure 6. Agile App Development Process at GenITeamss 


\section{Table 1}

GenITeams Divisions

\begin{tabular}{|c|c|}
\hline $\begin{array}{l}\text { Services } \\
\text { Division }\end{array}$ & Deals in outsourcing work in mobile applications and games; both 2D and 3D \\
\hline $\begin{array}{l}\text { The Game Boss } \\
\text { Division }\end{array}$ & $\begin{array}{l}\text { Focuses on } 2 \mathrm{D}+3 \mathrm{D} \text { Games Development in war, RPG's (Role Playing Games), } \\
\text { Escape series stream. It's a major product development stream and contributes } \\
\text { almost } 20-30 \% \text { of revenues. }\end{array}$ \\
\hline $\begin{array}{l}\text { Tapinator } \\
\text { Division }\end{array}$ & $\begin{array}{l}\text { A partnered division which is also a public limited Company in New York. It holds } \\
\text { investments from US investors that endorse them investment and portfolio control. } \\
\text { It has two further divisions in Rapid Development and Celebrity Games. }\end{array}$ \\
\hline $\begin{array}{l}\text { Rapid } \\
\text { Development }\end{array}$ & $\begin{array}{l}\text { Works on quick ideas developed in Lahore office. It's a major contributor to the } \\
\text { revenues of Tapinator. }\end{array}$ \\
\hline Celebrity Games & $\begin{array}{l}\text { Envisions in New York and it's a new area of growth. Tapinator deals in 3D } \\
\text { Gaming Development and carries multiple streams in racing, parking, animal } \\
\text { simulators, shooting and hunting games. }\end{array}$ \\
\hline
\end{tabular}

